\title{
Correspondence
}

\section{Plasma sufentanil concentration after intranasal administration to paediatric outpatients}

To the Editor:

Paediatric premedications are given reluctantly because of discomfort with im injection and commonly used sedatives can delay emergence from anaesthesia. Sufentanil, as a nasal spray, has been used successfully as a preinduction medication. Henderson, et al., ${ }^{1}$ demonstrated the effectiveness of premedicating children with nasal sufentanil and described a smooth perioperative course. Vercauteren et al. obtained stable vital signs and relieved preoperative anxiety with nasal sufentanil in adults. ${ }^{2}$

We prospectively studied the sufentanil plasma concentrations following nasal administration in paediatric outpatients. We gave 15 ASA I and II unpremedicated patients sufentanil, $2 \mu \mathrm{g} \cdot \mathrm{kg}^{-1}$, as nasal drops from a tuberculin syringe while the child was kept supine by the parent. No other opioids were given in the perioperative period. Ten minutes later the child was transferred to the OR for an inhalational induction of anaesthesia with nitrous oxide and halothane. Venous blood samples were collected in heparinized tubes at $15,30,60,90$, and 150 min after the sufentanil was given. Plasma sufentanil concentration was measured by a gas chromatography-mass spectrometry assay sensitive to $0.02 \mathrm{ng} \cdot \mathrm{ml}^{-1}$ sufentanil with a coefficient of variation $5-6 \% .^{3}$

All patients had a sufentanil concentration greater than $0.1 \mathrm{ng} \cdot \mathrm{ml}^{-1}$ at the first interval sampled. The highest measured plasma sufentanil concentration occurred 15 min after intranasal administration in eight patients and at $30 \mathrm{~min}$ in the other seven patients (Figure). The plasma concentration of sufentanil at $150 \mathrm{~min}$ was $<0.08$ $\mathrm{ng} \cdot \mathrm{ml}^{-1}$. This concentration corresponds to the clinical observations of sedation, analgesia, and pruritus.

Our experience with intranasal sufentanil is that it serves as an alternative method of premedication which facilitates the smooth induction of anaesthesia. While the onset of sedation is rapid, the peak plasma sufentanil concentrations may not occur for $30 \mathrm{~min}$. Sufentanil plasma concentrations associated with analgesia persist well into the postoperative period. The technique may, therefore, be inappropriate for short diagnostic procedures which are not associated with postoperative pain.

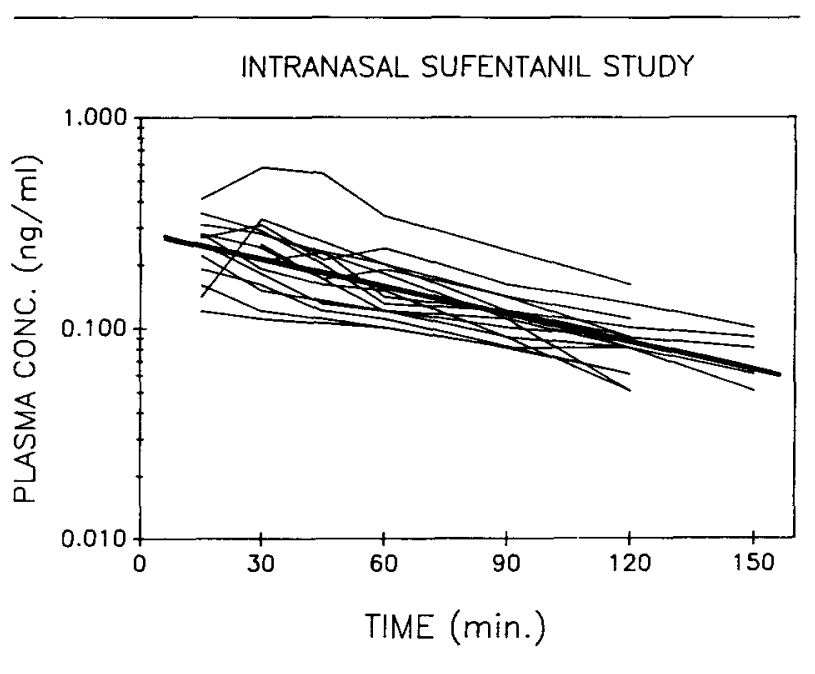

FIGURE Sufentanil plasma concentrations $\left(\mathrm{ng} \cdot \mathrm{ml}^{-1}\right)$ in each of 15 subjects measured between 15 and $150 \mathrm{~min}$ after intranasal dose. The heavy dark line is the linear regression of plasma concentration versus time for the group.

Gary Haynes PhD MD

Norman H. Brahen MD

Harlan F. Hill PhD

Department of Anesthesiology

Medical University of South Carolina

171 Ashley Avenue

Charleston, S.C. 29425

\section{REFERENCES}

1 Henderson JM, Brodsky DA, Fisher DM, Brett CM, Hertzka RE. Preinduction of anesthesia in pediatric patients with nasally administered sufentanil. Anesthesiology 1988; 68: 671.

2 Vercauteren M, Boeckx E, Hanegreefs G, Noorduin H, Vanden Bussche $G$. Intranasal sufentanil for preoperative sedation. Anaesthesia 1988; 43: 270.

3 Woestenborghs RJH, Stanski DR, Scott JC, Heykants $J J P$. Assay methods for fentanyl in serum: gas-liquid chromatography versus radioimmunoassay. Anesthesiology 1987; 67: 85 . 